\title{
Segregation Correlation of SSR Markers and Flower Traits in Aneuploid Tobacco
}

\author{
Chao Liu1, Jiangbo Dang1, Lingli Wang², Zhi Chen'1, Ying Wang1, Guanrong Li ${ }^{*}$, Guolu Liang1* \\ ${ }^{1}$ College of Horticulture and Landscape Architecture, Southwest University, Chongqing, China \\ ${ }^{2}$ Technical Advice Station of Economic Crop, Yubei District, Chongqing, China \\ ${ }^{3}$ College of Agronomy and Biotechnology, Southwest University, Chongqing, China \\ Email: *lianggl@swu.edu.cn, * ${ }^{*}$ rli@swu.edu.cn
}

How to cite this paper: Liu, C., Dang, J.B., Wang, L.L., Chen, Z., Wang, Y., Li, G.R. and Liang, G.L. (2018) Segregation Correlation of SSR Markers and Flower Traits in Aneuploid Tobacco. World Journal of Engineering and Technology, 6, 225-240. https://doi.org/10.4236/wjet.2018.62013

Received: December 28, 2017

Accepted: May 7, 2018

Published: May 10, 2018

Copyright (๑) 2018 by authors and Scientific Research Publishing Inc. This work is licensed under the Creative Commons Attribution International License (CC BY 4.0).

http://creativecommons.org/licenses/by/4.0/ (c) (i) Open Access

\begin{abstract}
Few reports have been seen on the segregation of polyploids and on the relationship between the segregation of SSR loci and that of the morphological traits in polyploid progeny. This paper attempted to gain an insight into the segregation of the hexaploid tobacco progeny and to understand the correlation of the segregation of SSR loci with that of the flower morphological traits. The segregation was evaluated with both SSR markers and morphological traits of the flowers. Twenty pairs of SSR primers were screened and a total of 42 SSR loci were identified. Chi-square analysis showed that the segregation ratio of the SSR loci in the aneuploid progeny was between 1:1 and 2:1. Six morphological traits of flowers, including the lengths of the flower and the calyx, the widths of the calyx, the corolla tube and the corolla, and the coloring of the flower, from 180 progeny and 2 progenitor plants, were determined and Chi-square analyzed. All traits were in consistent also with a segregation ratio of 1:1 to 2:1 except the width of the calyx.
\end{abstract}

\section{Keywords}

Hexaploid Tobacco, SSR Markers, Flower Morphological Traits, Segregation Correlation

\section{Introduction}

Polyploidy exist in plants as well as many animals and it is a universal phenomenon in natural conditions [1]. Polyploidization or whole-genome duplication (WGD) is regarded as a driving force in the processes of evolution [2] [3]. Polyploidization can trigger rapid genomic rearrangements, genomic downsizing, and movement of genetic elements across genomes, epigenetic remodeling such 
as DNA methylation changes and of foreign genetic materials into the polyploid genome, suggesting the complex dynamics of polyploid genomes [4]. These extensive changes in the genome of polyploidy may further give rise to new phenotype, transgressive traits and high resistance, etc. [5]. Lai et al. [6] analyzed one of the three hybrid species, Helianthus deserticola, by microarray, and revealed that approximately $2 \%$ of genes had extreme or transgressive expression in the hybrid species. These findings also showed that polyploidy may play an important role in the processes of evolution. Likewise, Soltis and Soltis [7] indicated that polyploidy played a major role in the evolution of many eukaryotes. About $70 \%$ of all angiosperms have experienced one or more episodes of polyploidization based on recent estimates [8]. Recent studies have focused on the high growth vigor in the polyploid which had been widely studied [9] [10].

Early studies on aneuploidy began with the Drosophila and Datura by Calvin Bridges who noted that individuals could have changes in chromosome number and was confirmatory of the chromosome theory of inheritance [11]. Compared with polyploidy, Aneuploidy plays an important role in the evolution of plants as well [12]. Some studies indicated that polyploidy may promote the formation of aneuploidy and these two are often intertwined in the evolution processes [13] [14]. In the genome of aneuploidy, loss of one or more chromosomes in aneuploidy can lead to dramatically changes of the stability of the genome, the effect of gene dosage and gene expression [15]. The meiosis of aneuploidy exhibits inordinate and the extra chromosome in aneuploidy may undergo a phenomenon of centromere misdivision [16]. Due to a series of changes in the genome of aneuploidy, aneuploidy is sterile and less fit than euploidy in many species under natural conditions, and even these are fatal [17] [18]. However, recent findings showed that aneuploid not only can generate many new phenotypes but also can revert back to stabilize euploidy, so they were regarded as the valuable materials by many breeders [19]. Although aneuploidy has an important role in the evolution processes and breeding as polyploidy does, we still know little about the mechanisms of the genomic changes and phenotype variations compared with polyploidy.

Tobacco is an annual herbaceous plant belonging to Solanaceae. Cultivated tobacco (Nicotiana tabacum L.) is not only an important economic crop but also a model system used in numerous studies of plant biology [20]. Since tobacco is 3 - 4 months per cycle, thousands of seeds per cross, large phenotypic diversity, and the cultivated tobacco is allotetraploid, it is an ideal material to investigate the mechanisms of genomic changes at the initial stage of aneuploidy formation.

In order to investigate the segregation pattern of chromosome among the aneuploidy hybrids, we used the model plant tobacco as material to generate an aneuploidy population, and then using 20 SSR markers to trace the distribution of different chromosome in the aneuploidy hybrids. The SSR markers were linkage to different chromosome and were obtained from the first linkage map of tobacco (http://solgenomics.net/cview/map.pl?map_id=15) which was released in 2007. By counting the number of bands of each SSR marker in the aneuploidy, 
the segregation ratios of the aneuploidy hybrids were calculated. We also had measured some morphological traits of flowers to further verify the segregation ratios of SSR markers and the result showed that the segregation of SSR markers and morphological traits of flowers were correlated.

\section{Materials and Methods}

\subsection{Plant Materials}

Cultivated tobacco is an allotetraploid. In order to obtain hexaploid tobacco for this study, seeds of the currently cultivated tobacco Yunyan 87 was treated with colchicine to obtain octoploid in vitro in our laboratory, and then the octoploid was used to cross another currently cultivated tobacco tetraploid L-8 to obtain the hexaploid tobacco, and finally the hexaploid was crossed with the tetraploid Yunyan 87 to obtain the $F_{2}$ progeny (Figure 1 ). The $F_{2}$ progeny of a hexaploid and a tetraploid would be pentaploid in theory. Actually, most of them were aneuploidy, confirmed cytologically in our laboratory. Because the hexaploid tobacco have three copies of each homeolog and this may generate multivalent when the homologous chromosomes synapsis in the meiosis. The abnormal meiosis will lead to abnormal chromosome numbers in the gametes and therefore aneuploid $\mathrm{F}_{2}$ progeny.

In this work, the segregation of an $\mathrm{F}_{2}$ population of 220 plants derived from a crossing between the hexaploid [(Yunyan $878 \times) \times(L-84 \times)$ ] and tetraploid (Yunyan 87 ) was mainly considered through the comparison with the progenitors (Yunyan 87 tetraploid and L-8 tetraploid). The flower morphological traits of the progenitors were shown in Table 1 . Yunyan 87 and L-8 tobacco tetraploids were chosen as references to determine transgressive traits occurring in the aneuploid population was mainly due to the fact that Yunyan 87 and L-8 tobacco tetraploids are the cultivated tobacco and that we wanted to get more beneficial morphological traits though repeated back crossing.

All the plant materials were grown in the Experimental Base of College of Horticulture and Landscape Architecture, Southwest University, China.

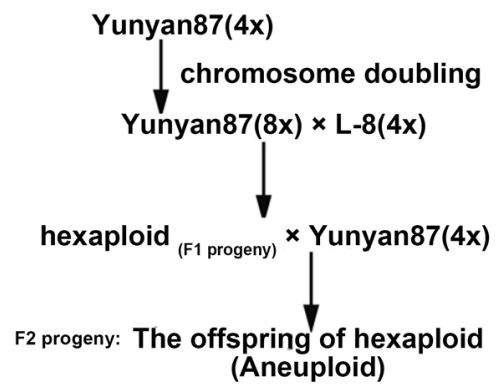

Figure 1. Crosses to obtain the hexaploid tobacco. All plants were planted in the open field. The ploidy of the hexaploid, octoploid and the $\mathrm{F}_{2}$ progenytobacco were detected by the cytological method. In our study, we mainly consider the segregation of the offspring of hexaploid through the comparison with the progenitors (Yunyan 87 tetraploid and L-8 tetraploid). 
Table 1. The flower morphological traits of the parental lines (Yunyan 87 and L-8).

\begin{tabular}{cccccc}
\hline Index & $\begin{array}{c}\text { Length of the } \\
\text { flower }(\mathrm{mm})\end{array}$ & $\begin{array}{c}\text { Length of the } \\
\text { calyx }(\mathrm{mm})\end{array}$ & $\begin{array}{c}\text { Width of the } \\
\text { calyx }(\mathrm{mm})\end{array}$ & $\begin{array}{c}\text { Width of the corolla } \\
\text { tube }(\mathrm{mm})\end{array}$ & $\begin{array}{c}\text { Width of the } \\
\text { corolla }(\mathrm{mm})\end{array}$ \\
\hline Yunyan 87 & $52.20 \pm 1.30$ & $17.53 \pm 0.41$ & $9.09 \pm 0.46$ & $4.70 \pm 0.13$ & $25.40 \pm 2.00$ \\
L-8 & $44.27 \pm 1.48$ & $16.66 \pm 0.53$ & $9.79 \pm 0.63$ & $5.21 \pm 0.21$ & $22.12 \pm 1.71$ \\
\hline
\end{tabular}

${ }^{\dagger}$ Mean \pm DE $(n=5)$.

\subsection{DNA Isolation and SSR Primers}

Genomic DNAs were extracted and purified from freeze-dried plant leave samples using a modified CTAB method [21]. Ninety pairs of primers flanking the SSR loci were derived from the report [22] and synthesized by Hua Da Gene Company. Twenty pairs of primers yielded clearly discernible and stable banding patterns and were thus selected for further analysis (Table 2).

\subsection{Chromosome Number Detection}

The chromosome number of the randomly selected 87 individuals was detected by the protocol described by Kurata and Omura [23] with minor modifications.

\subsection{PCR Amplification}

PCR reactions were performed in a total volume of $15 \mu \mathrm{L}$ containing $1.5 \mu \mathrm{L}$ of $10 \times$ PCR buffer (Takara Corp), $1.2 \mu \mathrm{L} \mathrm{MgCl}_{2}(25 \mathrm{mmol} / \mathrm{L}$, Takara Corp), $0.4 \mu \mathrm{L}$ dNTP (10 mmol/L, Takara Corp), $0.2 \mu \mathrm{L}$ Taq DNA Pol (5 U/ $\mu \mathrm{L}$ Takara Corp), $50 \mathrm{ng}$ template DNA and $1.5 \mu \mathrm{L}$ of each primer $(10 \mu \mathrm{mol} / \mathrm{L})$. Amplification was performed in a DNA Thermal Cycler for 30 cycles: 5 min denaturation at $94^{\circ} \mathrm{C}$, $94^{\circ} \mathrm{C}$ denaturation $40 \mathrm{~s}, 30 \mathrm{~s}$ at $56^{\circ} \mathrm{C}$ and $45 \mathrm{~s}$ at $72^{\circ} \mathrm{C}$ and all reactions contained a terminal elongation step of $72^{\circ} \mathrm{C}$ for $6 \mathrm{~min}$. The amplified SSR products were separated on $8 \%$ polyacrylamide gels and silver stained.

\subsection{Measurement of Flower Morphological Traits}

The morphological traits of the flowers from 180 progeny plants and the progenitors, including the length of the flower and calyx, the width of the calyx, corolla and corolla tube of 5 flowers per plant, were measured with vernier caliper [24] as shown in Figure 2. Each morphological trait was defined by the length or the width in its longest dimension and was categorized into four intervals in comparison with that of the progenitors. The size intervals of the five morphological traits were shown in Table 3.

The flower color was evaluated by eye and was divided into six levels from the lightest to the deepest also in comparison with the flower color of the progenitors, marked 1 through 6 from the least (lightest) red colored to the most (deepest) colored (Figure 3). The flower color of the parental lines, Yunyan 87 and L-8, was leveled 4 and 3 respectively. The color of five flowers per plant was determined. When the flower color of the progeny is lighter than L-8, it is marked " 1 " or "2" and when it is deeper than Yunyan 87, it is marked " 5 " or " 6 ". 
Table 2. Sequences of SSR primer pairs screened.

\begin{tabular}{|c|c|c|}
\hline SSR locus & Forward primer $\left(5^{\prime} \rightarrow 3^{\prime}\right)$ & Reverse primer $\left(5^{\prime} \rightarrow 3^{\prime}\right)$ \\
\hline РT30408 & TCGCTCAAACAACATTGAGG & ATTGCGCATGATGCATTG \\
\hline PT20213 & TGTGGAGCTCCTTTCTTTGC & TCAAATCAACAACAAATCCAAT \\
\hline PT20382 & TTCACAGGGTGGGAAAATGT & ACTCCTAAACCTCGCCCAAC \\
\hline PT20242 & TCCAAAGTTGGACCAGAA & GTCCTACATGGGGCTCTT \\
\hline РT30426 & CAACTATTGACCGATGTGGG & GTGTTTCATTTGATCTATGAATCTTT \\
\hline PT30403 & CCAACTCTACCGCTAACTTCAAA & CACGACTGACGAGACATGGT \\
\hline РТ30399 & TGTGTGCACCCTCCAATTTA & TGATCTCTAGAGTGGTGGCATC \\
\hline РT30235 & TTTCAGCCGTCACCTCTTCT & AGCGATGCAACAATGATGAG \\
\hline PT30171 & CCCATGCATGCCTAATTTCT & CCCAGAAGCCСТTATACAACC \\
\hline PT20189 & AAAGGTTCGGTATCCCAG & ATTGGACGATGAGAACGA \\
\hline PT30375 & TCCTCTACCCAACGTCAAGAA & GGCAAACCAGCTAGCACAT \\
\hline PT20172 & АСАССТССТТСТTССТGC & CCAAAATGGTTCACTGGA \\
\hline PT20372 & CCTTTACCTCCGACAATTTCA & TAGGCTGGATAGGTGCCTCA \\
\hline РT30394 & TCATTTGGTGGAATCAATGAA & GGCTTTGTGTTCGCCTACAT \\
\hline РT30138 & AGTTGCAGGATTGTTCGCTT & CGACTGCAAGAGTTGGCAAT \\
\hline РT30174 & TGGTCGATCAACATGACAAA & TCTAAATCACGCTGCATTGG \\
\hline PT30361 & AACCCGACCACTCCCTATCT & GTGGTTTAGTGGGAGCTTCG \\
\hline РT30382 & TGACGGATGGTCATTCATCTT & TCCTTCATAGGTAAAGTTAATGGATG \\
\hline PT30421 & CGTACCCTGAATGCCATCTT & ATGCAGCGTTTCAGGAATTT \\
\hline PT30372 & TGCACATGCTATGACGATTATCT & GGTCATTGATCGCCAAGTTT \\
\hline
\end{tabular}

Table 3. The intervals of the flower morphological traits in the $\mathrm{F}_{2}$ population of the hexaploid tobacco.

\begin{tabular}{cccccc}
\hline Index & $\begin{array}{c}\text { Transgressive } \\
\text { traits }(\mathrm{mm})\end{array}$ & $\begin{array}{c}\text { Resembling } \\
\text { Yunyan } 87 \\
(\mathrm{~mm})\end{array}$ & $\begin{array}{c}\text { Resembling L-8 } \\
(\mathrm{mm})\end{array}$ & $\begin{array}{c}\text { Transgressive } \\
\text { traits }(\mathrm{mm})\end{array}$ & $\begin{array}{c}\text { Segregation } \\
\text { ratio }\end{array}$ \\
\hline $\begin{array}{c}\text { Length of the } \\
\text { flower }\end{array}$ & $30.00-40.00^{6}$ & $50.00-60.00^{88}$ & $40.00-50.00^{65}$ & $60.00-80.00^{21}$ & $109 / 71 \approx 1.5: 1$ \\
$\begin{array}{c}\text { Length of the } \\
\text { calyx }\end{array}$ & $10.00-15.00^{16}$ & $17.00-20.00^{56}$ & $15.00-17.00^{55}$ & $20.00-30.00^{53}$ & $109 / 71 \approx 1.8: 1$ \\
$\begin{array}{c}\text { Width of the } \\
\text { calyx }\end{array}$ & $4.00-8.33^{93}$ & $8.33-9.33^{49}$ & $9.33-10.33^{23}$ & $10.33-12.33^{15}$ & $142 / 38 \approx 3.7: 1$ \\
$\begin{array}{c}\text { Width of the } \\
\text { corolla tube } \\
\text { Width of the } \\
\text { corolla }\end{array}$ & $3.00-4.00^{5}$ & $4.00-5.00^{96}$ & $5.00-6.00^{74}$ & $6.00-8.00^{5}$ & $101 / 79 \approx 1.3: 1$ \\
\hline
\end{tabular}

${ }^{\top}$ The numbers of the progeny plants in intervals are indicated by superscripts.

\subsection{Data Recording and Analysis}

SSR markers were manually scored as binary data with presence as "1" and absence as "0". Bands shared between progenitors and $\mathrm{F}_{2} \mathrm{~s}$ were not counted. 


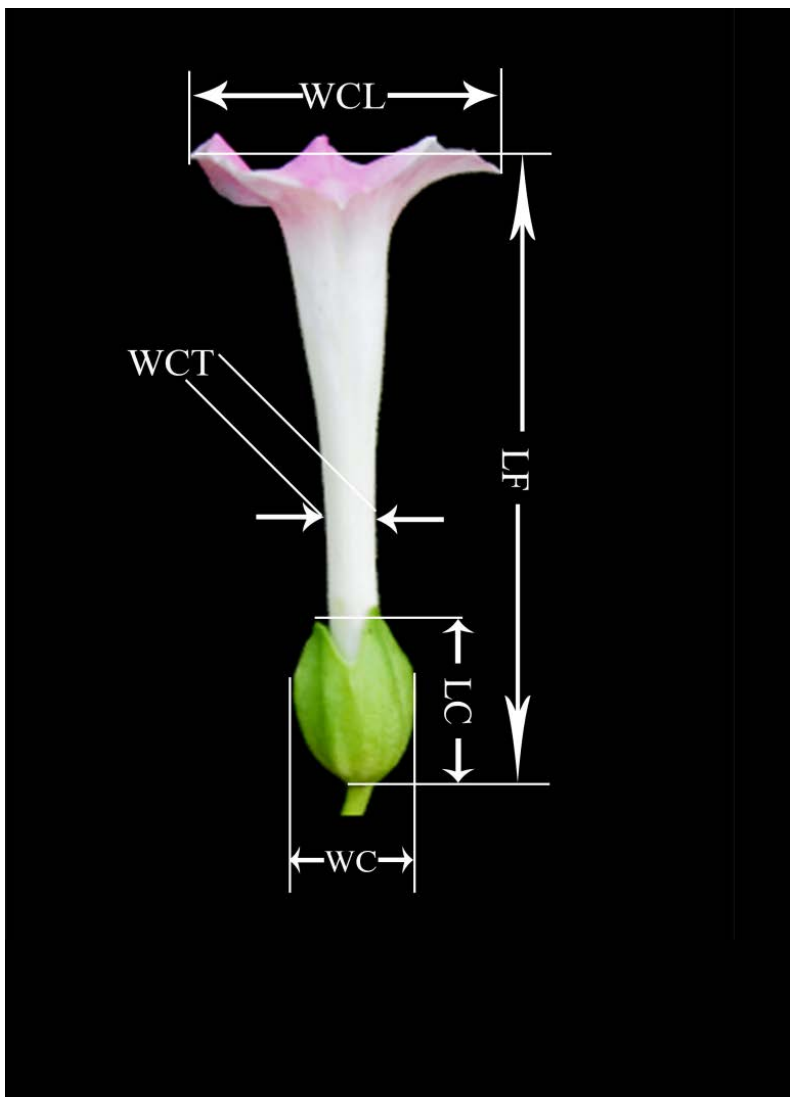

Figure 2. Methodology of morphologies measurement. LF: Length of the flower; LC: Length of the calyx; WC: Width of the calyx; WCL: Width of the corolla; WCT: Width of the corolla tube; All were measured by vernier caliper.
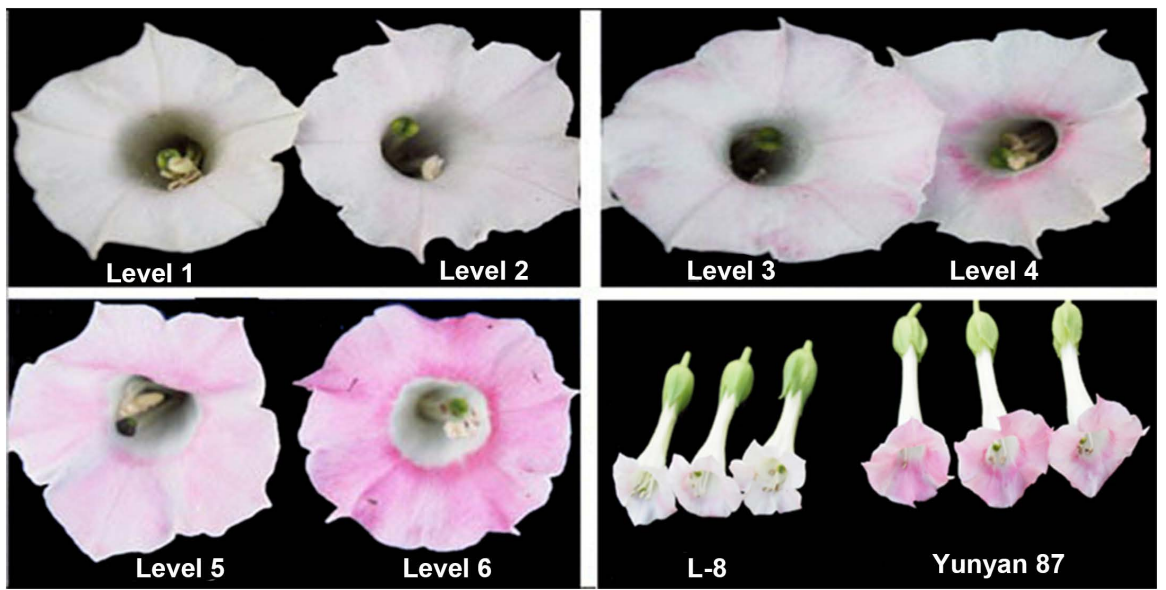

Figure 3. The coloring levels for flowers. The flower color was evaluated by eye and was divided into six levels, marked 1 through 6 from the least (lightest) red colored to the most (deepest) colored based on the color depth of the progenitors. The color of five flowers per plant was determined.

The segregation of SSR loci in the $\mathrm{F}_{2}$ population was subjected to Chi-square analysis to test the goodness-of-fit to the expected Mendel's segregation ratio in 
the Excel, Microsoft office 2010. Chi-square detected different segregation levels $(1: 1,1.5: 1$ and $2: 1)$ by setting the Chi-square probability function $\mathrm{P}\left(>\chi^{2}\right)=0.050$ as a significance level, as shown in the following equation:

$$
\chi_{c}^{2}=\sum_{i=1}^{k} \frac{\left(\left|O_{i}-E_{i}\right|-0.5\right)^{2}}{E_{i}}
$$

Genetic similarity coefficients of the 220 progeny plants with the progenitors were also processed in Excel. The SPSS was employed to analyze the number in each interval defined previously. The segregation of flower morphological traits was obtained through the equation:

$$
\text { Segregation ratio }=\left(R_{1}+T_{1}\right) /\left(R_{2}+T_{2}\right)
$$

where, $R_{1}, R_{2}$ : the number of the progeny plants with morphological trait resemble Yunyan 87 or L-8 respectively; $T_{1}, T_{2}$ : the number of the progeny plants with morphological trait transgressive over $R_{1}$ or $R_{2}$ respectively.

\section{Results}

\subsection{Chromosome Number Detection}

The chromosome number of 87 individual plants were detected. Result showed that the chromosome number variation ranged from 46 to 76 and the statistical analysis showed a normal distribution (Figure 4). Furthermore, most of them were aneuploidies, only 6 pentaploid individuals. The ratio of euploid was $6.9 \%$. This cytological result was consistent with the ploidy assumption above.

\subsection{SSR Polymorphism}

A total of 20 primer pairs were screened to genotype both the progenitors and 220 progeny plants. A typical amplification profile is shown in Figure 5. All together, 42 polymorphic SSR markers was generated, an average of 2 polymorphic bands for each pair of primers. The expected sizes of amplification products varied from 100 to $300 \mathrm{bp}$. The progeny resembling Yunyan 87 and L-8 was defined as genetic similarity coefficient well above 0.5 , to each, respectively. The similarity coefficient data showed that most progeny (188 plants, $85.45 \%$ in percentage) resembled Yunyan 87, and 32 progeny plants resembled L-8, with a percentage of only $14.55 \%$ (Figure 6).

\subsection{Segregation of the SSR Loci}

The segregation of each locus of the 42 SSR loci was tested by Chi-square analysis. Based on the hypothesis that when half of the progeny plants resemble $\mathrm{Yu}$ nyan 87 or L-8, the segregation ratio of the progeny plants would be 1:1, SSR segregation levels of 1.5:1 and 2:1 with the interval length of 0.5 were detected. The results showed that there were 23 loci in line with the Chi-square analysis of 1:1 and 17 were in line with the Chi-square analysis of 1.5:1. Only two loci were found to be in line with the Chi-square analysis of 2:1 (Table 4). The results 


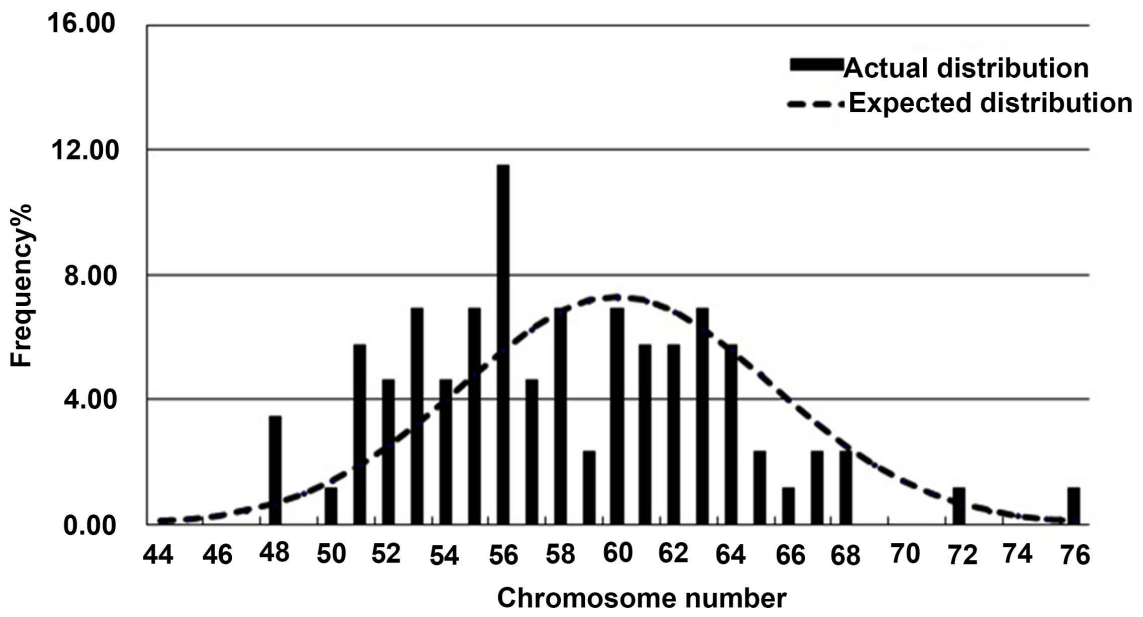

Figure 4. The chromosome number variation of the 87 offspring. The result showed that the chromosome number of the 87 offspring ranged from 46 to 76 and showed a normal distribution.

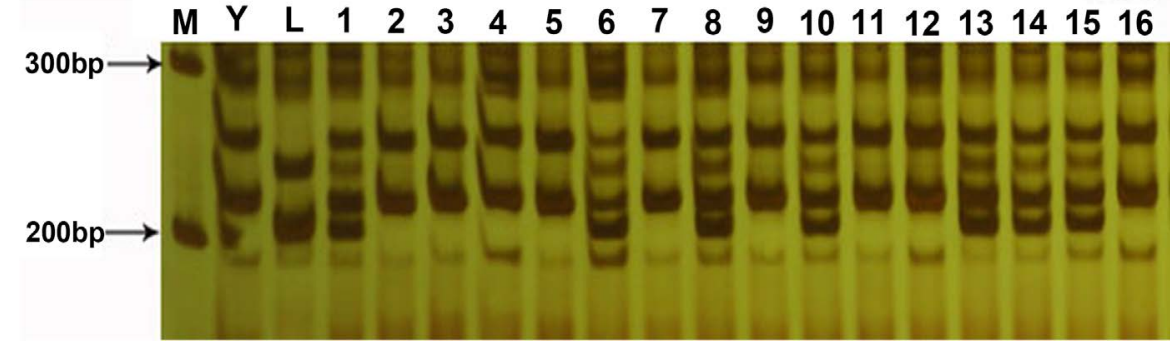

Figure 5. A typical amplification profile by PT30421 SSR primer pair. M: 100 bp ladder molecular weight markers; Y: Yunyan 87; L: L-8; Lanes 1-16: the serial number of the $\mathrm{F}_{2}$ progeny plants.

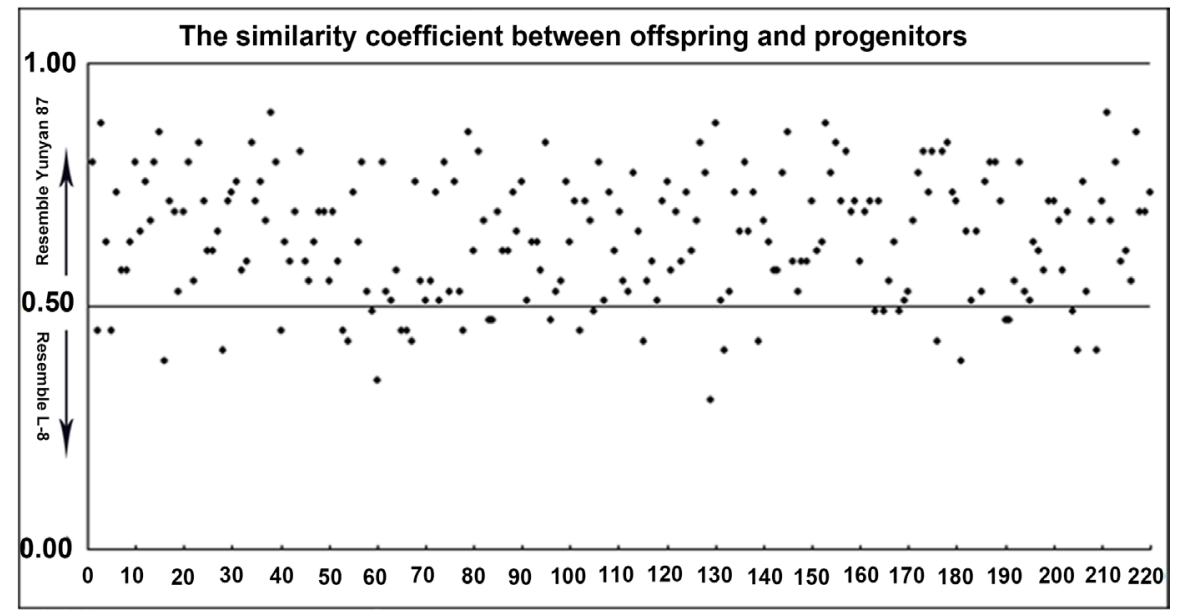

Figure 6. The similarity coefficient between offspring and progenitors. The $\mathrm{X}$ axis indicates the number of the offspring and the $\mathrm{Y}$ axis represents the similarity coefficient between the offspring and progenitors.

suggest that the segregation ratio of the SSR loci in the progeny was between 1:1 and $2: 1$. 
Table 4. Segregation analysis of the 42 SSR loci in the $\mathrm{F}_{2}$ population of the hexaploid tobacco.

\begin{tabular}{|c|c|c|c|c|c|}
\hline Locus & Observed frequency & $\chi^{2}(1: 1)$ & $x^{2}(1.5: 1)$ & $\chi^{2}(2: 1)$ & Linkage group \\
\hline PT30408 & $130: 90$ & $6.91^{0}$ & $0.043^{1}$ & $5.58^{0}$ & Chromosome 10 \\
\hline РT30408 & $130: 90$ & $6.91^{0}$ & $0.043^{1}$ & $5.58^{0}$ & Chromosome 10 \\
\hline РT30408 & $127: 93$ & $4.95^{\circ}$ & $0.38^{1}$ & $7.80^{\circ}$ & Chromosome 10 \\
\hline PT20213 & 118:102 & $1.02^{1}$ & $3.45^{1}$ & $16.65^{0}$ & Chromosome 12 \\
\hline PT20382 & 105:115 & $4.85^{0}$ & $13.30^{\circ}$ & $35.31^{0}$ & Chromosome 12 \\
\hline PT20382 & 106:114 & $0.22^{1}$ & $12.32^{0}$ & $33.63^{0}$ & Chromosome 12 \\
\hline PT20382 & 106:114 & $0.22^{1}$ & $12.32^{0}$ & $33.63^{0}$ & Chromosome 12 \\
\hline PT20382 & 106:114 & $0.22^{1}$ & $12.32^{0}$ & $33.63^{0}$ & Chromosome 12 \\
\hline PT20382 & $106: 114$ & $0.22^{1}$ & $12.32^{0}$ & $33.63^{0}$ & Chromosome 12 \\
\hline PT20382 & 105:115 & $0.37^{1}$ & $13.30^{\circ}$ & $35.31^{0}$ & Chromosome 12 \\
\hline PT20382 & 105:115 & $0.37^{1}$ & $13.30^{\circ}$ & $35.31^{0}$ & Chromosome 12 \\
\hline PT20242 & 107:113 & $0.11^{1}$ & $11.37^{0}$ & $31.99^{0}$ & Chromosome 12 \\
\hline PT30426 & $134: 86$ & $10.04^{0}$ & $0.043^{1}$ & $3.20^{1}$ & Chromosome 12 \\
\hline РT30403 & $124: 96$ & $3.31^{1}$ & $1.07^{1}$ & $10.38^{0}$ & Chromosome14a \\
\hline РТ30399 & 119:101 & $1.31^{1}$ & $2.96^{1}$ & $15.50^{\circ}$ & Chromosome 17 \\
\hline РТ30399 & 119:101 & $1.31^{1}$ & $2.96^{1}$ & $15.50^{\circ}$ & Chromosome 17 \\
\hline РТ30399 & 119:101 & $1.31^{1}$ & $2.96^{1}$ & $15.50^{\circ}$ & Chromosome 17 \\
\hline РТ30399 & 119:101 & $1.31^{1}$ & $2.96^{1}$ & $15.50^{\circ}$ & Chromosome 17 \\
\hline РТ30235 & $127: 93$ & $4.95^{0}$ & $0.38^{1}$ & $7.80^{\circ}$ & Chromosome 21 \\
\hline РТ30235 & $127: 93$ & $4.95^{0}$ & $0.38^{1}$ & $7.80^{\circ}$ & Chromosome 21 \\
\hline РТ30235 & $163: 57$ & $50.11^{0}$ & $17.62^{0}$ & $4.93^{0}$ & Chromosome 21 \\
\hline РT30171 & 108:112 & $0.04^{1}$ & $10.46^{0}$ & $30.39^{0}$ & Chromosome 24 \\
\hline РT30171 & $163: 57$ & $50.11^{0}$ & $17.62^{0}$ & $4.93^{0}$ & Chromosome 24 \\
\hline РТ30171 & 110:110 & $0.0045^{1}$ & $8.75^{0}$ & $27.31^{0}$ & Chromosome 24 \\
\hline PT20189 & 117:103 & $0.77^{1}$ & $3.98^{0}$ & $17.84^{0}$ & Chromosome 1 \\
\hline PT20189 & 116:104 & $0.55^{1}$ & $4.55^{0}$ & $19.07^{0}$ & Chromosome 1 \\
\hline PT20189 & 118:102 & $1.02^{1}$ & $3.45^{1}$ & $16.65^{0}$ & Chromosome 1 \\
\hline РТ30375 & $132: 88$ & $8.40^{\circ}$ & $0.0047^{1}$ & $4.31^{0}$ & Chromosome 2 \\
\hline PT20172 & $173: 47$ & $71.02^{0}$ & $31.07^{0}$ & $13.33^{0}$ & Chromosome 3a \\
\hline PT20172 & $174: 46$ & $73.31^{0}$ & $32.62^{0}$ & $14.40^{\circ}$ & Chromosome $3 \mathrm{a}$ \\
\hline PT20172 & $184: 36$ & $98.22^{0}$ & $50.23^{0}$ & $27.31^{0}$ & Chromosome $3 \mathrm{a}$ \\
\hline PT20172 & 102:118 & $1.02^{1}$ & $16.48^{0}$ & $40.60^{0}$ & Chromosome $3 \mathrm{a}$ \\
\hline PT20172 & $177: 43$ & $80.40^{\circ}$ & $37.50^{\circ}$ & $17.84^{0}$ & Chromosome $3 \mathrm{a}$ \\
\hline PT20172 & $189: 31$ & $112.04^{0}$ & $60.46^{0}$ & $35.31^{0}$ & Chromosome $3 \mathrm{a}$ \\
\hline PT20372 & $123: 97$ & $2.84^{1}$ & $1.37^{1}$ & $11.32^{0}$ & Chromosome $3 \mathrm{a}$ \\
\hline PT20372 & $205: 15$ & $162.37^{0}$ & $99.55^{0}$ & $67.78^{0}$ & Chromosome 3a \\
\hline PT30361 & 107:113 & $0.11^{1}$ & $11.37^{0}$ & $31.99^{0}$ & Chromosome $8 \mathrm{~b}$ \\
\hline РT30361 & $107: 113$ & $0.11^{1}$ & $11.37^{0}$ & $31.99^{0}$ & Chromosome 8b \\
\hline РT30361 & 107:113 & $0.11^{1}$ & $11.37^{0}$ & $31.99^{0}$ & Chromosome $8 \mathrm{~b}$ \\
\hline PT30382 & $152: 68$ & $31.31^{0}$ & $7.20^{\circ}$ & $0.42^{1}$ & Chromosome 9 \\
\hline РT30421 & $131: 89$ & $7.64^{0}$ & $0.0047^{1}$ & $4.93^{0}$ & Chromosome 9 \\
\hline РT30421 & $131: 89$ & $7.64^{0}$ & $0.0047^{1}$ & $4.93^{0}$ & Chromosome 9 \\
\hline Total & & $23^{2}$ & $17^{2}$ & $2^{2}$ & \\
\hline
\end{tabular}

${ }^{+0}$ The segregation of the locus not in accordance with the indicated Chi-square analysis. ${ }^{{ }^{1}}$ The segregation of the locus in accordance with the indicated Chi-square analysis. ${ }^{52} \mathrm{The}$ total number of the loci in accordance with the indicated Chi-square analysis. 


\subsection{Segregation of Flower Morphological Traits}

The flower morphological traits of the 180 progeny plants and their progenitors were measured with vernier caliper. Morphological data of the progenitors ( $\mathrm{Yu}-$ nyan 87 and L-8) and the $\mathrm{F}_{2}$ plants were shown respectively in Table 1 and Table 3.

The lengths and widths of the progeny flowers were divided into four continuous intervals based on the lengths and widths of the progenitors, two of which representing the transgressive traits, and the other two, representing the traits resembling Yunyan 87 or L-8 (Table 3). For the length of the progeny flowers, about 6 progeny belonged to the interval of $30-40 \mathrm{~mm}$, and 21 progeny belonged to $60-80 \mathrm{~mm}, 88$ progeny resembled the progenitor Yunyan 87 and 65 progeny resembled L-8, with a segregation ratio of ca. 1.5:1, consistent with the segregation ratio of the SSR loci discussed above; for the length of the calyx, 56 progeny resembled Yunyan 87 and 55 progeny resembled L-8, with a segregation ratio of ca. 1.8:1, also consistent with the SSR loci; For the width of the calyx, most progeny belonged to the transgressive traits and fewer resembled L-8, with a segregation ratio of $3.7: 1$; for the widths of the corolla tube and the corolla, the segregation ratios were 1.3:1 and 1.1:1 respectively.

The number of the progeny whose flower color resembled L-8 was 56, and the number of progeny whose flower resembled Yunyan 87 was 100 (Figure 7). The segregation of the color is $1.8: 1$.

All the segregation ratios fell into the range of 1:1 to 2:1, a slight bias being the width of the calyx.

In conclusion, twenty pairs of SSR primers screened out 42 loci in total and the segregation ratio of the SSR markers were between 1:1 and 2:1. The segregation of the 6 flower morphological traits was also fallen into 1:1 and 2:1 except the width of the calyx. The segregation of SSR markers and the flower morphological traits both were consistent with the theoretically deduced ratio of segregation. SSR will be one of the powerful tools for genetic studies and marker-assisted tobacco breeding and there are great potentials yet to be developed. As many transgressive morphological traits of the hexaploid tobacco flowers have been detected in this research, the adaptability of some of the progeny might have been improved.

\section{Discussion}

Tobacco is not only an important agronomic crop in the large family of Solanaceae, but also a model plant frequently used in plant biology [25]. SSR markers have been developed and adopted to evaluate genetic diversity in a tobacco collection by $\mathrm{Wu}$ et al. [26]. Polyploid segregation ratios have been detected at 4 microsatellite loci in the diploid and polyploid Ipomoea [27]. These studies proved that the SSR markers are stable and applicable.

In this study, the correlation between the segregation of SSR loci and the segregation of the six morphological traits of flowers in aneuploid tobacco, has 

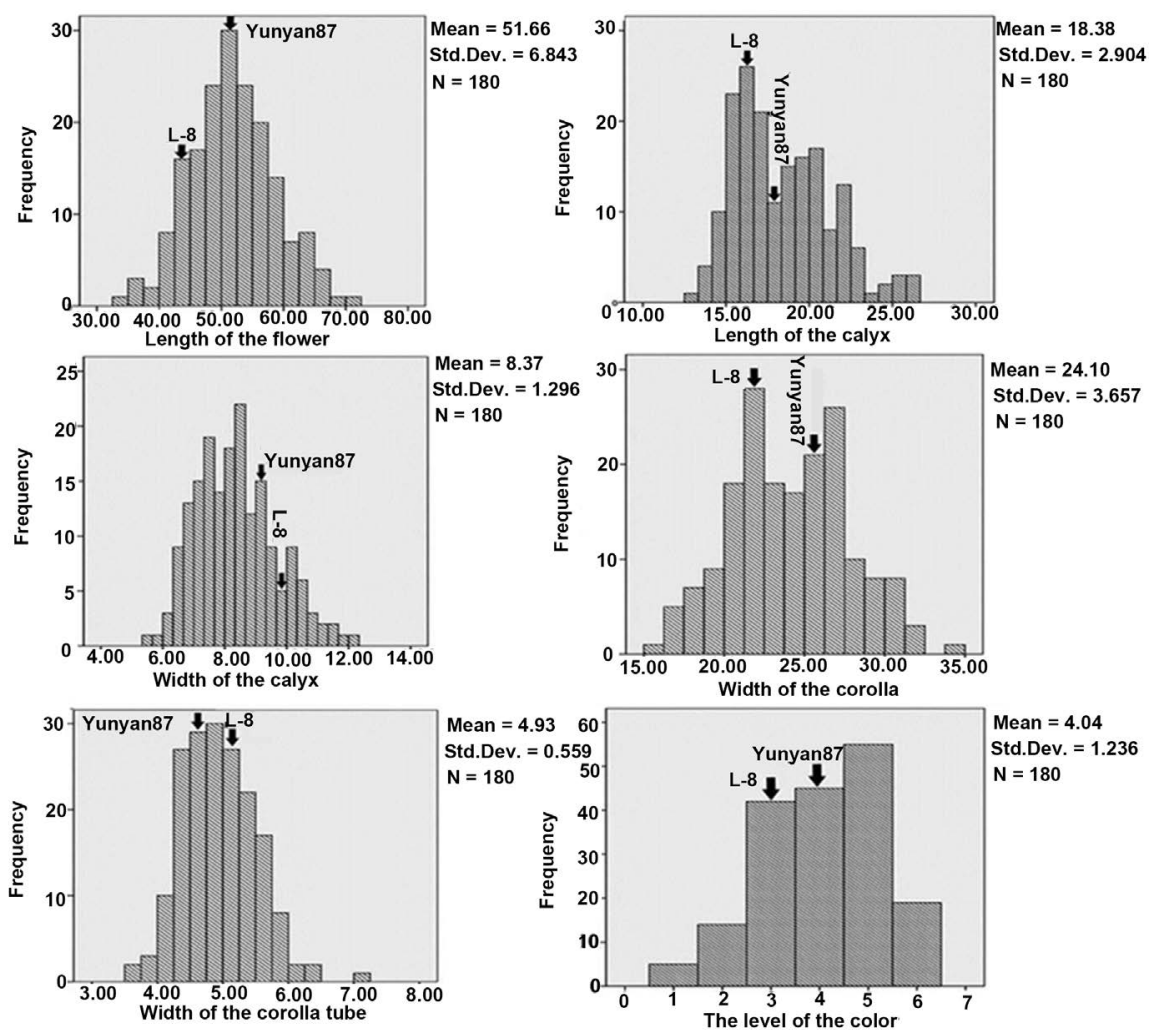

Figure 7. The segregation of flower morphological traits of the 180 progeny plants analyzed by SPSS. Traits included the length of the flower, length of the calyx, width of the calyx, width of the corolla tube, width of the corolla and the level of the color. The $\mathrm{X}$ axis indicates the length or width of flower or the degree of flower coloring and the $\mathrm{Y}$ axis indicates the frequency of each column.

been established. To our knowledge, our result represents the first report on the close accordance of segregation based on SSR markers with that based on the morphological traits in polyploid progeny.

Polyploidy is a prominent and significant force in plant evolution, at temporal scales ranging from ancient to contemporary, and with profound effects at scales ranging from molecular to ecological [28]. Hybrids are formed by cross-fertilization between different individuals, strains, or species. Hybrids often grow more vigorously and produce more seeds and offspring than the parents. This phenomenon is known as hybrid vigor or heterosis [29]. Findings made in the last two decades have revealed that the early stages of allopolyploidy are often associated with rapid and extensive genomic instabilities, which are thought to be important for initial stabilization of the newly formed allopolyploids as well as contribute to their establishment as competitive new species [30] [9]. The materials used in this study came from a series of polyploid hybridization. What is more, most of the hybrids are aneuploids and thus a variety of morphological traits may appear in the population. Therefore, these hybrids are very precious and suitable for studying genomic evolution of the polyploidy.

SSR loci were used to investigate gametic segregation [31]. In fact, hexaploid 
tobacco can be treated as triploid. Because $N$. tabacum tetraploids are disomic, therefore hexaploids are trisomic. Trivalents between homeologs from one progenitor genome are expected during meiosis. Homeologs from different progenitor genomes do not pair in meiosis. Otto and Whitton [32] reported that triploid plants generally give rise to aneuploidy gametes which exhibit very low fertility. So the hexaploid may produce different types of the gametes in theory. Based on the linkage analysis of the $\mathrm{F}_{2}$ population of hexaploid tobacco, the 42 loci isolated were subject to Chi-square test to probe the segregation of the progeny. The resulting segregation was 1:1 to 2:1.

The segregation ratios of the six traits were fallen into the theoretic value with only one exception, the width of the calyx, which apparently showed matroclinous and/or gene interactive effect of the progenitors, as has been reported by $\mathrm{Yu}$ et al. [33]. Wissemann [34] indicated the primary cause for matroclinous inheritance: hybridization caused asymmetric meiosis, the reason for heterogamy is asymmetrical, mostly matroclinous inheritance of characters and character states, but not vice versa. The apparently higher mutation rate found in the gene flanking regions in the progenitors might be associated with the complex polyploid nature of these species, which could induce chromosome pairing aberrations [35]. The polyploid has a tendency of being diploidized. The higher mutation may also be related with the progeny's maintaining of the chromosome balance [36]. Reasons for the segregation ratio of the width of the calyx not consistent with the theoretic value might be the change of gene function or nucleotide sequence variations in the expressed regions [37].

The phenotypes exhibiting in hybrids that are extreme or novel relative to the parental lines are called transgressive traits [38]. The progeny plants studied in this paper all displayed transgressive characters in all six traits examined. Chen [5] had proposed two models at gene expression level to explain heterosis in allopolyploids and hybrids: the dominance model and the overdominance model. The dominance model suggests that the expression of genes in the hybrids is a result of combined or additive expression of two alleles in the parents (e.g., $1+1$ $=2$ ), whereas the overdominance model indicates that allelic interactions in the hybrids lead to nonadditive expression of the alleles derived from the parents (1 $+1 \neq 2$ ). If the interactions lead to positive effects or gene activation, the outcome is expected to be $1+1>2$. If the interactions result in negative effects or gene repression, the expected outcome would be $1+1<2$. Nonadditive expression explains positive as well as negative epistatic interactions. Otherwise, dosage regulation may also affect the phenotypic variation [39]. It has been suggested that additive effects in polyploidys lead to increase or decrease levels of gene expression and phenotypic variation. The reasons for a variety of morphological traits appeared in the hexaploid progeny may be even more intricate than the discussions shown above.

Schwarzbach et al. [40] studied 41 morphological traits using the hybrid $\mathrm{He}$ lianthus anomalus obtained from the crossing of $H$. annuus with the $H$. petiolaris, and found that in Helianthus anomalus, only 1 trait was morphologically in- 
termediate (2.4\%), 23 traits, parents-like (56.1\%), and 17 traits, transgressive (41.5\%). Rieseberg et al. [41] gave four possible predictions to explain transgression, based on the assumption that complementary gene action is the main cause for transgression. Baack and Rieseberg [42] suggested that transgressive segregation could occur when parental species contain alleles with opposing effects. From the evolutionary point of view, the transgressive characters might also be very beneficial to the adaptive evolution [43].

It should be noted that although in this paper the correlation between SSR markers segregation and flower morphological traits segregation in aneuploid tobacco has been established, the correlation of SSR markers segregation with other morphological traits need further investigation.

\section{Acknowledgements}

This work was supported by Breeding of Special Flavored, Excellent Quality and Disease-resistant Novel Flue-cured Tobacco Varieties in Chongqing Mountainous Region (No. 2012044). The authors are thankful to Professor Qiao He, Misses Hui Luo and Tianjiao Wu (College of Horticulture and Landscape Architecture, Southwest University) for their assistance in constructing the $\mathrm{F}_{2}$ population and the measurement of the morphological traits.

\section{Conflict of Interest}

The authors declare that they have no conflict of interest.

\section{References}

[1] Matzke, M.A., Mette, M.F., Kanno, T. and Matzke, A.J. (2003) Does the Intrinsic Instability of Aneuploid Genomes Have a Causal Role in Cancer? Trends in Genetics, 19, 253-256. https://doi.org/10.1016/S0168-9525(03)00057-X

[2] Chen, Z.J. and Ni, Z. (2006) Mechanisms of Genomic Rearrangements and Gene Expression Changes in Plant Polyploids. BioEssays, 28, 240-252. https://doi.org/10.1002/bies.20374

[3] Soltis, P.S. and Soltis, D.E. (2009) The Role of Hybridization in Plant Speciation. Annual Review of Plant Biology, 60, 561-588. https://doi.org/10.1146/annurev.arplant.043008.092039

[4] Soltis, D.E., Soltis, P.S. and Tate, J.A. (2003) Advances in the Study of Polyploid since Plant Speciation. New Phytologist, 161, 173-191. https://doi.org/10.1046/j.1469-8137.2003.00948.x

[5] Chen, Z.J. (2010) Molecular Mechanisms of Polyploidy and Hybrid Vigor. Trends in Plant Sciences, 15, 57-71. https://doi.org/10.1016/j.tplants.2009.12.003

[6] Lai, Z., Gross, B.L., Zou, Y., Andrews, J. and Rieseberg, L.H. (2006) Microarray Analysis Reveals Differential Gene Expression in Hybrid Sunflower Species. Molecular Ecology, 15, 1213-1227. https://doi.org/10.1111/j.1365-294X.2006.02775.X

[7] Soltis, D.E. and Soltis, P.S. (1999) Polyploid: Recurrent Formation and Genome Evolution. Reviews, 14, 348-352.

[8] Masterson, J. (1994) Stomatal Size in Fossil Plants: Evidence for Polyploid in Majority of Angiosperms. Science, 264, 421-424. 
https://doi.org/10.1126/science.264.5157.421

[9] Chen, Z.J. (2007) Genetic and Epigenetic Mechanisms for Gene Expression and Phenotypic Variation in Plant Polyploids. Annual Review of Plant Biology, 58, 377-406. https://doi.org/10.1146/annurev.arplant.58.032806.103835

[10] Meyer, R.C., Witucka-Wall, H., Becher, M., Blacha, A., Boudichevskaia, A., Dörmann, P., Fiehn, O., Friedel, S., Von Korff, M., Lisec, J., Melzer, M., Repsilber, D., Schmidt, R., Scholz, M., Selbiq, J., Willmitzer, L. and Altmann, T. (2012) Heterosis Manifestation during Early Arabidopsis Seedling Development Is Characterized by Intermediate Gene Expression and Enhanced Metabolic Activity in the Hybrids. The Plant Journal, 71, 669-683. https://doi.org/10.1111/j.1365-313X.2012.05021.x

[11] Bridges, C.B. (1916) Non-Disjunction as Proof of the Chromosome Theory of Heredity. Genetics, 1, 1-52.

[12] Henry, I.M., Dilkes, B.P., Young, K., Watson, B., Wu, H. and Comai, L. (2005) Aneuploidy and Genetic Variation in the Arabidopsis thaliana Triploid Response. Genetics, 170, 1979-1988. https://doi.org/10.1534/genetics.104.037788

[13] Stebbins, G.L. (1971) Chromosomal Evolution in Higher Plants. Edward Arnold, London.

[14] Otto, S.P. (2007) The Evolutionary Consequences of Polyploidy. Cell, 131, 452-462. https://doi.org/10.1016/j.cell.2007.10.022

[15] Tamara, A.P., Zhu, J. and Li, R. (2013) Aneuploidy and Chromosomal Instability: A Vicious Cycle Driving Cellular Evolution and Cancer Genome Chaos. Cancer and Metastasis Reviews, 32. https://doi.org/10.1007/s10555-013-9436-6

[16] Birchler, J.A. (2013) Aneuploidy in Plants and Flies: The Origin of Studies of Genomic Imbalance. Seminars in Cell \& Developmental Biology, 24, 315-319. https://doi.org/10.1016/j.semcdb.2013.02.004

[17] Torres, E.M., Sokolsky, T., Tucker, C.M., Chan, L.Y., Boselli, M., Dunham, M.J. and Amon, A. (2007) Effects of Aneuploidy on Cellular Physiology and Cell Division in Haploid Yeast. Science, 317, 916-924. https://doi.org/10.1126/science.1142210

[18] Henry, I.M., Dilkes, B.P., Miller, E.S., Burkart-Waco, D. and Comai, L. (2010) Phenotypic Consequences of Aneuploidy in Arabidopsis thaliana. Genetics, 186, 1231-1245. https://doi.org/10.1534/genetics.110.121079

[19] Zhang, H., Bian, Y., Gou, X., Dong, Y., Rustgi, S., Zhang, B., Xu, C., Li, N., Qi, B. and Han, F. (2013) Intrinsic Karyotype Stability and Gene Copy Number Variations May Have Laid the Foundation for Tetraploid Wheat Formation. Proceedings of the National Academy of Sciences, 110, 19466-19471. https://doi.org/10.1073/pnas.1319598110

[20] Bindler, G., Hoeven, R.V.D., Gunduz, I., Plieske, J., Ganal, M., Rossi, L., Gadani, F. and Donini, P. (2007) A Microsatellite Marker Based Linkage Map of Tobacco. Theoretical and Applied Genetics, 114, 341-349. https://doi.org/10.1007/s00122-006-0437-5

[21] Moon, H.S., Nicholson, J.S. and Lewis, R.S. (2008) Use of Transferable Nicotiana tabacum L. Microsatellite Markers for Investigation Genetic Diversity in the Genus Nicotiana. Genome, 51, 547-559. https://doi.org/10.1139/G08-039

[22] Liang, J.X., Qi, A.M., Wu, W.R., Zhou, D., Chen, S., Wang, T. and Tao, A. (2005) DNA Extraction and the Establishment of SRAP Reaction System in Tobacco. Acta Tabacaria Sinica, 11, 33-38.

[23] Kurata, N. and Omura, T. (1978) Karyotype Analysis in Rice. The Japanese Journal 
of Genetics, 4, 251-255. https://doi.org/10.1266/jig.53.251

[24] Ashfaq, M., Khan, A.S., Khan, S.H.U. and Ahmad, R. (2012) Association of Various Morphological Traits with Yield and Genetic Divergence in Rice (Oryza sativa). International Journal of Agriculture \& Biology, 14, 55-62.

[25] Bindler, G., Plieske, J., Bakaher, N., Gunduz, I., Ivanov, N., Van der Hoeven, R., Ganal, M. and Donini, P. (2011) A High Density Genetic Map of Tobacco (Nicotiana tabacum L.) Obtained from Large Scale Microsatellite Marker Development. Theoretical and Applied Genetics, 123, 219-230. https://doi.org/10.1007/s00122-011-1578-8

[26] Wu, F., Eannetta, N.T., Xu, Y., Plieske, J., Ganal, M., Pozzi, C., Bakaher, N. and Tanksley, S.D. (2010) COSII Genetic Maps of Two Diploid Nicotiana Species Provide a Detailed Picture of Synteny with Tomato and Insights into Chromosome Evolution in Tetraploid N. tabacum. Theoretical and Applied Genetics, 120, 809-827. https://doi.org/10.1007/s00122-009-1206-Z

[27] Buteler, M.I., Jarret, R.L. and LaBonte, D.R. (1999) Sequence Characterization of Microsatellites in Diploid and Polyploid Ipomoea. Theoretical and Applied Genetics, 99, 123-132. https://doi.org/10.1007/s001220051216

[28] Adams, K.L. and Wendel, J. (2005) Polyploidy and Genome Evolution in Plants. Current Opinion in Plant Biology, 8, 135-141. https://doi.org/10.1016/j.pbi.2005.01.001

[29] Darwin, C.R. (1876) The Effects of Cross- and Self-Fertilization in the Vegetable Kingdom. John Murry, London.

[30] Wendel, J.F. (2000) Genome Evolution in Polyploids. Plant Molecular Biology, 42, 225-249.

[31] Lashermes, P., Combes, M.C., Ansaldi, C., Gichuru, E. and Noir, S. (2011) Analysis of Alien Introgression in Coffee Tree (Coffea arabica L.). Molecular Breeding, 27, 223-232. https://doi.org/10.1007/s11032-010-9424-2

[32] Otto, S.P. and Whitton, J. (2000) Polyploid Incidence and Evolution. Annual Review of Genetics, 34, 401-437. https://doi.org/10.1146/annurev.genet.34.1.401

[33] Yu, Q.X., Shao, J.Z. and Xu, J.Z. (2010) The Relationship between the Lenticel Character of Apple Rootstock Hybrids and Anti-Infection of Botryosphaeria berengeriana f. piricola. Journal of Agricultural University of Hebei, 33, 21-25.

[34] Wissemann, V. (2005) Evolution by Hybridisation. The Influence of Reticulate Evolution on Biosymmetrical Patterns and Processes in Plants. Theory in Biosciences, 123, 223-233. https://doi.org/10.1016/j.thbio.2004.09.003

[35] Magoon, M.L., Krishnan, R. and Bai, K.V. (1970) Cytological Evidence on the Origin of Sweet Potato. Theoretical and Applied Genetics, 40, 360-366. https://doi.org/10.1007/BF00285415

[36] Jauhar, P.P. (1975) Genetic Regulation of Diploid-Like Chromosome Pairing in the Hexaploid Species, Festuca arundinacea Schreb. and F. rubra L. (Gramineae). Chromosoma, 52, 363-382.

[37] Bowman, J. (1997) Evolutionary Conservation of Angiosperm Flower Development at the Molecular and Genetic Levels. Journal of Biosciences, 22, 515-527. https://doi.org/10.1007/BF02703197

[38] Rieseberg, L.H., Widmer, A., Arntz, A.M. and Burke, J.M. (2003) The Genetic Architecture Necessary for Transgressive Segregation Is Common in Both Natural and Domesticated Populations. Philosophical Transactions of the Royal Society of London, 358, 1141-1147. https://doi.org/10.1098/rstb.2003.1283 
[39] Birchler, J.A., Bhadra, U., Bhadra, M.P. and Auger, D.L. (2001) Dosage-Dependent Gene Regulation in Multicellular Eukaryotes: Implications for Dosage Compensation, Aneuploid Syndromes, and Quantitative Traits. Developmental Biology, 234, 275-288. https://doi.org/10.1006/dbio.2001.0262

[40] Schwarzbach, A.E., Donovan, L.A. and Rieseberg, L.H. (2001) Transgressive Character Expression in a Hybrid Sunflower Species. American Journal of Botany, 88, 270-277. https://doi.org/10.2307/2657018

[41] Rieseberg, L.H., Archer, M.A. and Wayne, R.K. (1999) Transgressive Segregation, Adaptation and Speciation. Heredity, 83, 363-372. https://doi.org/10.1038/sj.hdy.6886170

[42] Baack, E.J. and Rieseberg, L.H. (2007) A Genomic View of Introgression and Hybrid Speciation. Current Opinion in Genetics \& Development, 17, 513-518. https://doi.org/10.1016/j.gde.2007.09.001

[43] Barton, N.H. (2001) The Role of Hybridization in Evolution. Molecular Ecology, 10, 551-568. https://doi.org/10.1046/j.1365-294x.2001.01216.x 